\title{
Characterisation of Extended $\beta$-Lactamases and Plasmid Mediated Quinolones Resistancein Escherichia Coli from Shelter Dogs
}

\author{
Andreea Paula COZMA ${ }^{1 *}$, Elena Iuliana Măciucă${ }^{2}$, Cătălin CARP-CĂRARE ${ }^{1}$, Mihai CARP-CĂRARE ${ }^{1}$, \\ Cristina RÎMBU ${ }^{1}$, Adriana ANIȚĂ ${ }^{1}$, Dragoș ANIȚ $\breve{A}^{1}$, Dorina TIMOFTE ${ }^{1,2}$ \\ ${ }^{1}$ Department of Public Health, "Ion Ionescu de la Brad" University of Agricultural Sciences and Veterinary \\ Medicine Iasi, Romania \\ ${ }^{2}$ Institute of Veterinary Science, University of Liverpool, United Kingdom \\ *corresponding author: andreeapaulacozma@yahoo.com
}

Bulletin UASVM Veterinary Medicine 76(1)/2019

Print ISSN 1843-5270; Electronic ISSN 1843-5378

doi:10.15835/buasvmcn-vm: 2019.0003

\begin{abstract}
The aim of this study was to determine the prevalence of $\beta$-lactamase (TEM, SHV, OXA), extended-spectrum $\beta$-lactamase (ESBL) and genes encoding plasmid mediated resistance to quinolones (PMQR) in extended spectrum cephalosporin (ESC)-resistant Escherichia coli isolated from dog faeces from two shelters in the North-East of Romania. Eighty-eight faecal samples from healthy dogs were analysed by cultivation on Brilliance ESBL medium (Oxoid, UK), followed by phenotipic ESBL screening using combination disc test (CDT). Identification of the E. coli strains was performed by uidA/uspA gene PCR. Susceptibility testing was performed on Mueller-Hinton Agar, with $\beta$-lactam and non- $\beta$-lactam agents. Identification of $\beta$-lactamase genes $\left(b l a_{\mathrm{CTX}-\mathrm{M}^{\prime}}, b l a_{\mathrm{TEM}}, b l a_{\mathrm{SHV}}, b l a_{\mathrm{OXA}}\right)$ and PMQR genes ( $q n r A, q n r B$ and $q n r S$ ) was performed by PCR as previously described. Twenty eight ESCresistant E. coli $(31.81 \%)$ were obtained and $(\mathrm{n}=21 / 28,75 \%)$ of these were confirmed as ESBLs and showed resistance to cefpodoxime ( $\mathrm{n}=21 / 28,75 \%)$, amoxicillin/clavulanic acid $(\mathrm{n}=19 / 21 ; 90.48 \%)$, and enrofloxacin ( $n=8 / 21 ; 38.09 \%)$. Predominant ESBL types were CTX-M-1 (n=15/17, 88.24\%) and CTX-M-9 (n=2/17, 11.76\%) enzymes. TEM and SHV enzymes were identified in $17.86 \%$ and $14.29 \%$ of the ESC-resistant isolates, whilst some isolates $(\mathrm{n}=4)$ carried only $b l a_{\mathrm{TEM}}$ and $b l a_{\mathrm{SHV}}$. The prevalence of PMQR genes was $28.57 \%$ of the 28 ESC resistant isolates, consisting of $q n r S(62.5 \%)$ and $q n r B(37.5 \%)$. These findings indicate a high prevalence of ESBLs and $\mathrm{PMQR}$ associated resistance $E$. coli in the normal faecal microbiota of dogs from shelters, which carries the risk for dissemination of these resistance genes to other animals, human or the environment.
\end{abstract}

Keywords: CTX-M, PMQR, SHV, TEM, dogs

\section{Introduction}

ESBLs enzimes confer resistance to extendedspectrum cephalosporins (ESCs) and monobactams and often express a resistance to non- $\beta$-lactam antimicrobials such as fluoroquinolones leaving only limited therapeutic options (Pitout et al., 2008). Escherichia coli strains colonize the digestive track both in animals, and in humans. Resistance to ESC is one of the characteristics commonly seen in E. coli strains, representing an issue both for human and animal health (Ljungquist et al., 2016). The change of faecal microbiota in dogs, with increased resistance and carriage of ESBL producing E. coli isolates is more prevalent with most dogs being intermittently shedders and positive carriers for various ESBL genes (Baede et al., 2015). Several studies have shown that the most common type of ESBL enzyme isolated from dog faecal microbiota was CTX-M-15 a predominant subtype both in humans and in 
animals, including in livestock and wild animals (Brolund et al.,2016; Ewers et al., 2012; Guenther et al., 2011). Bacterial resistance to antibiotics, seen in Enterobacteriaceae strains isolated from dogs, may represent a potential risk for public health due to potential of being a reservoir of resistant bacteria for people with whom animals may come in direct contact (physical injuries, petting licking) or indirect contact (contamination of the household environment) (Guardabassi et al., 2004). With the exception of a study looking at antibiotic resistance of $E$. coli strains isolated from chicken (Măciucă et al., 2015) characterization of ESC-resistance resistance in animals has received less attention in Romania.

The aim of this work was to characterise antimicrobial resistance among $E$. coli isolated from dog faeces from two shelters in the NorthEast of Romania, with an emphasis on extended spectrum cephalosporin (ESC) resistance. The main focuse was to determine the prevalence of $\beta$-lactamase (TEM, SHV, OXA), extended-spectrum $\beta$-lactamase (ESBL) and genes encoding plasmid mediated resistance to quinolones (PMQR) in ESCresistant $E$. coli isolated from healthy dogs.

\section{Materials and methods}

Eighty-eight faecal samples were collected from healthy dogs from two shelters from the North-East of Romania using sterile rectal swabs. The primary processing consisted of performing the E. coli ESBL producing screening using the Brilliance ESBL medium (Oxoid, Basingstoke, UK), a medium that contains cefpodoximes. The isolates that generated colonies characteristic of $E$. coli on the medium used for screening were molecularly confirmed as being $E$. coli based on the uidA and uspA genes (McDaniels et al., 1996; Anastasi et al., 2010) and phenotypically confirmed as being ESBL using the combination disc test (CDT) ( MAST Group, UK). Also, all E. coli isolated on the Brilliance ESBL medium were tested for susceptibility to $\beta$-lactam and non- $\beta$-lactam agents through the diffusimetric method using Mueller-Hinton Agar (all disks and media from Oxoid, UK). The ATCC 25922 E. coli strain was used as control for the disk diffusion susceptibility test. The antimicrobials tested were as the follows: amoxicillin/clavulanic acid $(30 \mu \mathrm{g})$, ampicillin $(10 \mu \mathrm{g})$, aztreonam $(30 \mu \mathrm{g})$, imipenem $(10 \mu \mathrm{g})$, trimethoprim/sulfamethoxazole $(25 \mu \mathrm{g})$, enrofloxacin $(5 \mu \mathrm{g})$, tetracycline $(30 \mu \mathrm{g})$, chloramphenicol $(30 \mu \mathrm{g})$ and gentamicin $(10 \mu \mathrm{g})$.

Cell lysates obtained from all investigated isolates were screened by PCR for the presence of genes encoding for $\beta$-lactamase genes ( $b l a_{\text {Стх-M' }}$ $\left.b l a_{\mathrm{TEM}}, b l a_{\mathrm{SHV}}, b l a_{\mathrm{OXA}}\right)$ and PMQR (qnrA, qnrB and qnrS) as previously described (Wedley et al., 2011; Dallenne et al., 2010; Robicsek et al., 2006).

A PCR scheme described by Clermont et al was used to assign the ESBL E. coli isolates to one of the 4 main phylogenetic groups (A, B1, B2, D). (Clermont et al., 2000)

\section{Results and discussions}

Eighty-eight faecal samples collected from the two shelters were analysed and screened for ESBL production. Results showed that , 28/88 (31.81\%) ESC-resistant E. coli isolates were obtained and, of these, 21 isolates (75\%) were phenotypically confirmed as extended-spectrum $\beta$-lactamase enzyme-producing strains. The antimicrobial susceptibility test was carried out for the 21 phenotypically positive ESBL isolates which demonstrated high levels of resistance to ampicillin (100\% of them), amoxicillin/clavulanic acid (90.48\%; 19/21), aztreonam (85.71\%; $18 / 21)$ and tetracycline $(47.62 \% ; 10 / 21)$. In addition, $38.09 \%(8 / 21)$ of isolates were was resistant to both enrofloxacin and trimethoprim/ sulfamethoxazol whilst $14.29 \%(3 / 21)$ were resistant to chloramphenicol. All strains analysed using the diffusimetric test were susceptible to imipenem and chloramphenicol.

Molecular testing showed that bla $_{\text {CTX-M }}$ genes were identified in $17 / 28(60.71 \%)$ of ESC-resistant E. coli isoaltes, 15 of which (88.24\%) belonged to the CTX-M-1 group and only two (11.76\%) to the CTX-M-9 group. No genes belonging to groups $b l a_{\text {СТХ-м-2, }}, b l a_{\text {СТХ-м-8, }}$ and $b l a_{\text {CTX-M-25 }}$ were identified. In addition, 5/28 (17.86\%) E. coli isolates carried $b l a_{\text {ТЕм' }}$ and 4/28 (14.29\%) carrying bla $a_{\mathrm{SHV}}$ were identified, while $b l a_{\mathrm{OXA}}$ was not identified in any ESC-resistant E. coli strain (table 1).

The investigations for the PMQR genes showed that $8 / 28(28.57 \%)$ of the analysed isolates were positive, qnrS being the most prevalent gene, which was carried by $5 / 8(62.5 \%)$ isolates; this was followed by $q n r B$, which was carried by $3 / 8$ (37.5\%) ESC-resistant E. coli (table 1). The qnrA was not identified for the analysed isolates. 
In regard to the identified gene combinations, $b l a_{\text {СTX-M-1 }}$ has been identified both in combinations with PMQR genes (qnrS, qnrB, TEM) and alone for 7 of the 15 carrying bla ${ }_{\text {CTX-M-1 }}$ isolates(table 1). Also, 4 of the 28 of E. coli analysed only harboured $b l a_{\mathrm{TEM}}$ and $b l a_{\mathrm{SHV}}$ gene combination.

Phylogenetic analysis showed that most ESC-resistant E. coli isolates belonged to the phylogenetic group A (12/28; 42.86\%), followed by group B1 (10/28; 35.71\%), B2 (4/28; 14.29\%) and the phylogenetic group D $(2 / 28 ; 7.14 \%)$.

All CTX-M enzymes are part of the extendedspectrum $\beta$-lactamase (ESBL) enzyme group, while the TEM and SHV enzymes, could be either $\beta$-lactamase or ESBLs (Ewers et al., 2011). Although we did not perform PCR product sequencing on the 4 of the 28 ESC-resistant E. coli isolates which carries $b l a_{\text {TЕM }}$ and $b l a_{\mathrm{SHV}}$ genes, phenotypic combination disc test (CDT) testing showed a typic ESBL phenotype in this isolates. Consequently, this study has identified a high prevalence $(21 / 28$; $75 \%)$ of extended-spectrum $\beta$-lactamase (ESBL) enzyme-producing $E$. coli isolates associated with the production of genes encoding the plasmid mediated resistance to quinolones, in the normal microbiota of healthy dogs.

Also, in our study, the most prevalent enzyme group was CTX-M-1, which was the most common enzyme identified in chicken, pets and also urban healthy dogs (Dahmen et al., 2012; Grami et al., 2013; Zurfluh et al., 2014; Haenni et al., 2014).

Although the number of analysed samples is small, the high prevalence of ESBL positive E. coli isolates identified in this study highlights the occurance and likely circulation of these genes among healthy animals from shelters. This may also suggest that the unresricted circulation of these dogs could facilitate the dissemination of these resistance isolates/genes in animal populations and between species.

Finally, the identification and characterisation of the main genes encoding ESBL enzymes in dog populations, stray or pets in Romania has epidemiological imporatance as this is the first study to evaluate their prevalence in this population. Knowledge of the sources and reservoirs for these genes is essential in order to reduce the risks of transmission to humans. In addition, better policies and guidelines for apppropriate antimicrobial use are critical and need to be implemented in Romania to reduce the impact of selective pressure associated with antimicrobial use in veterinary medicine.

\section{Conclusions}

These findings indicate a high prevalence of ESBLs and PMQR associated resistance E. coli

Table 1. Prevalence and distribution of resistance gene combinations in Enterobacteriaceae strains isolated

\begin{tabular}{|c|c|c|}
\hline Source & bla gene combinations & No. of isolates/group \\
\hline \multirow{13}{*}{ dog } & Total CTX-M (\%)* & $17 / 28(60.71 \%)$ \\
\hline & CTX-M-1 group (\%) & $15 / 17(88.24 \%)$ \\
\hline & CTX-M-1 & $7 / 15(46.66 \%)$ \\
\hline & CTX-M-1, qnrS & $4 / 15(26.67 \%)$ \\
\hline & CTX-M-1, qnrS, TEM & $1 / 15(6.67 \%)$ \\
\hline & CTX-M-1, qnrB & $3 / 15(20 \%)$ \\
\hline & CTX-M-9 group (\%)* & $2 / 17(11.76 \%)$ \\
\hline & Total TEM (\%)* & $5 / 28(17.86 \%)$ \\
\hline & TEM, SHV & $4 / 28(14.29 \%)$ \\
\hline & Total SHV (\%) * & $4 / 28(14.29 \%)$ \\
\hline & Total PMQR genes & $8 / 28(28.57 \%)$ \\
\hline & qnrS & $5 / 8(62.5 \%)$ \\
\hline & qnrB & $3 / 8(37.5 \%)$ \\
\hline
\end{tabular}

Note: * is the percentage of the screened gene present in any combination in the analysed groups (dogs) 
in the normal microbiota of dogs from shelters, which carries the risk for dissemination of resistance genes to other animals, humans or the environment.

\section{References}

1. Anastasi EM, Matthews B, Gundogdu A, Vollmerhausen TL, Ramos NL, Stratton H, Ahmed W, Katouli1 M. (2010) Prevalence and Persistence of Escherichia coli Strains with Uropathogenic Virulence Characteristics in Sewage Treatment Plants. Applied and Environmental Microbiology, 76 (17): 5882-5886.

2. Baede V, Wagenaar JA, Broens EM, Duim B, Dohmen W, Nijsse R, et al. (2015) Longitudinal study of extended-spectrum- $\beta$-lactamase- and AmpC producing Enterobacteriaceae in household dogs. Antimicrob Agents Chemother, 59:3117-24.

3. Brolund A, Sandegren L (2016) Characterization of ESBL disseminating plasmids., Infect. Dis. (Lond) 48: 18-25.

4. Clermont O, Bonacorsi S, Bingen E (2000) Rapid and Simple Determination of the Escherichia coli Phylogenetic Group. Applied and Environmental Microbiology, 66(10): 4555-4558.

5. Dahmen S, Haenni M, Madec JY (2012) IncI1/ ST3plasmidscontributeto the dissemination of the bla CTX-M-1 gene in Escherichia coli from several animal species in France. J Antimicrob Chemother, 67:30113012.

6. Dallenne C, Costa DA, Decre D, Favier C, Arle G (2010) Development of a set of multiplex PCR assays for the detection of genes encoding important b-lactamases in Enterobacteriaceae. J Antimicrob Chemother, 65: 490495.

7. Ewers C, Bethe A, Semmler T, Guenther S, Wieler LH. (2012) Extended-spectrum $\beta$-lactamase-producing and AmpCproducing Escherichia coli from livestock and companion animals, and their putative impact on public health: a global perspective. Clin Microbiol Infect;18:646-55.

8. Ewers C., Grobbel M., A. Bethe, Wieler L.H., Guenther S., 2011- Extended-spectrum beta-lactamases-producing Gram-negative bacteria in companion animals: action is clearly warranted!, Berliner Und Munchener Tierarztliche Wochenschrift, 124: 94-101.

9. Grami R, Mansour W, Dahmen S, Mehri W, Haenni M, Aouni M, Madec JY. (2013). The bla CTX-M-1 IncI1/ST3 plasmid is dominant in chickens and pets in Tunisia. J Antimicrob Chemother, 68:2950 -2952.
10. Guardabassi L, Schwarz S, Lloyd DH (2004) Pet animals as reservoirs of antimicrobial-resistant bacteria. J. Antimicrob. Chemother, 54: 321-332.

11. Guenther S, Ewers C, Wieler LH. (2011) Extendedspectrum beta-lactamases producing E. coli in wildlife, yet another form of environmental pollution?, Front Microbiol., 2:246.

12. Haenni M, Saras E, Métayer V, Médaille C, Madec JY (2014) High Prevalence of blaCTX-M-1/IncI1/ST3 and blaCMY-2/ IncI1/ST2 Plasmids in Healthy Urban Dogs in France. Antimicrobial Agents and Chemotherapy, 58(9): 53585362.

13. Ljungquist 0 , Ljungquist D, Myrenas M, Cecilia Ryden, Maria Finn, Bengtsson B (2016) Evidence of household transfer of ESBL-/pAmpC producing Enterobacteriaceae between humans and dogs- a pilot study, Infection Ecology and Epidemiology, 6: 31514

14. Măciucă IE, Williams NJ, Tuchilus C, Dorneanu O, Guguianu E, Carp-Carare C, Rimbu C, Timofte D (2015) High Prevalence of Escherichia coli-Producing CTX-M-15 Extended-Spectrum Beta-Lactamases in Poultry and Human Clinical Isolates in Romania. Microbial Drug Resistance, 6: 651-662.

15. McDaniels AE, Rice E, Reyes A, Johnson CH, Haugland RA, Stelma GN Jr (1996). Confirmational Identification of Escherichia coli, a Comparison of Genotypic and Phenotypic Assays for Glutamate Decarboxylase and b-DGlucuronidase. Applied and Environmental Microbiology, 62 (9): 3350- 3354.

16. Pitout JD, Laupland KB, (2008) Extended-spectrum $\beta$-lactamase-producing Enterobacteriaceae: an emerging public-health concern. Lancet Infect. Dis.,8 (3): 159-166.

17. Robicsek A, Strahilevitz J, Sahm DF, Jacoby GA, Hooper DC (2006) qnr Prevalence in Ceftazidime-Resistant Isolates from the United States. Antimicrobial Agents and Chemotherapy, 50(8): 2872-2874.

18. Wedley AL, Maddox TW., Westgarth C, Coyne KP, Pinchbeck GL, Williams NJ, Dawson S (2011) Prevalence of antimicrobial-resistant Escherichia coli in dogs in across- sectional, community-based study.Vet. Rec., 168: 354-360.

19. Zurfluh K, Wang J, Klumpp J, Nuesch-Inderbinen M, Fanning S, Stephan R. (2014) Vertical transmission of

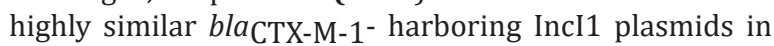
Escherichia coli with different MLST types in the poultry production pyramid. Front Microbiol, 5:519. 